\title{
Knowledge and perceptions of the NMSA role in Australia: A perioperative staff survey
}

Follow this and additional works at: https://www.journal.acorn.org.au/jpn

Part of the Health Services Administration Commons, Health Services Research Commons, Perioperative, Operating Room and Surgical Nursing Commons, and the Surgery Commons

(c) (i)

This work is licensed under a Creative Commons Attribution 4.0 License.

\section{Recommended Citation}

Hains, Toni; Turner, Catherine; and Strand, Haakan (2017) "Knowledge and perceptions of the NMSA role in Australia: A perioperative staff survey," Journal of Perioperative Nursing: Vol. 30 : Iss. 3 , Article 2. Available at: https://doi.org/10.26550/2209-1092.1017

https://www.journal.acorn.org.au/jpn/vol30/iss3/2

This Article is brought to you for free and open access by Journal of Perioperative Nursing. It has been accepted for inclusion in Journal of Perioperative Nursing by an authorized editor of Journal of Perioperative Nursing. 


\section{Authors}

Toni Hains

MClinSc (PNSA), MNPractSt, RN

The University of Queensland, School of Nursing, Midwifery and Social Work

\section{Catherine Turner}

PhD, RN

Professor of Nursing, The University of Queensland, School of Nursing, Midwifery and Social Work

Haakan Strand

PhD, MNPractSt, RN

Program Director - Master of Nurse Practitioner Studies, The University of Queensland, School of Nursing, Midwifery and Social Work

\section{Corresponding author}

Toni Hains

School of Nursing, Midwifery and Social Work

Level 3, Chamberlain Building,

The University of Queensland

St Lucia, QLD 4072

E: s4277231@student.uq.edu.au

T: +61 405469463

\section{Knowledge and perceptions of the NMSA role in Australia: A perioperative staff survey}

\begin{abstract}
In Australia, the role of the NonMedical Surgical Assistant (NMSA) lacks recognition and professional regulation. This paper reports the findings of a recent survey of Australian perioperative staff $[n=116]$ to determine their knowledge and perceptions of the NMSA role. The survey findings confirm that the role is not well established across the Australian health care system. of concern is that perioperative staff are required to fill the role of surgical assistant on an impromptu basis. NMSAs with no post-graduate qualifications are perceived by perioperative staff to be less equipped in mentoring, leadership, theatre efficiency, safety and procedural knowledge. There was evidence that some perioperative praxes necessitate the role of the NMSA to avoid practices that compromise patient safety.
\end{abstract}

Keywords surgical assistant, NonMedical Surgical Assistant, survey, perioperative practice, Australian health care system, scope of practice

\section{Introduction}

Practising perioperative nurses work in a relatively flat hierarchy in the clinical setting in which their roles are largely dictated by differences in the context of care. On occasion, variances in contexts and resources require Registered Nurses (RNs) to perform roles, such as surgical assisting, not typically associated with their scope of practice and this is a reflection of the leadership often displayed by perioperative clinicians $^{1-3}$. Recently, the role of
Nurse Practitioner (NP) has paved the way for nurses to expand their autonomy and scope of practice into the realm of other health care disciplines. As many possible Advanced Practice Nursing (APN) roles emerge in the Australian health care context, perioperative nurses will be required to consider the role of the NMSA and its relationship to scope of practice within the perioperative environment. Perioperative nurses may be able to develop pathways towards the role of the NMSA in ways that assure equality of cost and care delivery with those who currently perform the role ${ }^{1,4-6}$. This paper investigates the knowledge, perceptions and need for the role of NMSA in Australia.

\section{Background}

In a recent study on the role of the NMSA in Australia, it was reported that only RNS and NPS were performing the role $e^{5,7,8}$. The role of the NMSA presents a potential domain for advanced practice in Australia, particularly for perioperative nurses ${ }^{9}$. Depending on the qualification of the clinician, the scope of their practice and degree of autonomy they have may vary within the bounds of national or state legislation ${ }^{10,11}$.

In a recent practice audit of the role of the NMSA in Australia only RNs and NPS responded as performing the role of the NMSA ${ }^{12}$. Since orthopaedic and general surgery are the most commonly performed surgeries in Australia it was anticipated that orthopaedic surgery would have the highest NMSA involvement 
and general surgery the second highest ${ }^{13}$. This was confirmed by a recent practice audit of NMSAs in Australia ${ }^{12}$.

Advantages and disadvantages associated with the role of NMSA have been identified in the literature.

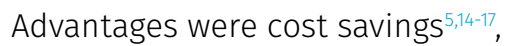
better access to medical care ch,15,18 $^{14-17}$ ${ }^{24}$, contributions to operating theatre and hospital proficiencies ${ }^{5}$, and positive influence on novice doctor training through added supervision ${ }^{8,25-29}$. Disadvantages identified were related to capability to perform advanced tasks ${ }^{14,20,29}$, education and continuing evaluation of the NMSA ${ }^{25,29-32}$.

In a study conducted in New Zealand on the role of the NMSA, most of those training for the role felt supported by other perioperative nurses, non-nursing staff and surgeons. The majority of surgeons who were surveyed as part of this report also felt the NMSAs were supported by other nursing staff. One surgeon and one NMSA from the private sector strongly disagreed that nursing and non-nursing colleagues understood or supported the role ${ }^{33}$. A paper generated from the implementation of NMSAs for public lists in a private hospital program in Australia highlighted that both perioperative staff and surgeons were very supportive and positive about the role of the NMSA ${ }^{34}$.

Very little literature exists about the opinions or perceptions of key stakeholders such as perioperative staff. Nurses, in particular, constitute a large proportion of the health care profession so surveying nurses on health-related research can yield valuable information ${ }^{35}$.

\section{Aim}

The aim of this study was to survey perioperative nurses' knowledge and perceptions of the role of the NMSA to identify current perioperative practice relevant to the role of the NMSA.

\section{Method}

This research takes the form of a descriptive, quantitative paper using survey method with convenience sample. Data analysis is descriptive. Institutional ethics approval for the survey was obtained from The University of Queensland (\#2015000084). Permission from the Australian College of Operating Room Nurses (ACORN) to administer the survey at the national conference was obtained. Implied consent was achieved by participants progressing through the survey to final submission.

\section{Participants and sampling}

Convenience sampling was adopted for this survey. As the total population of perioperative staff in Australia is difficult to accurately estimate, a sampling frame of the perioperative population who attended the 2016 ACORN National Conference was used. Using a specialty association of this type for sampling is time efficient and the researcher can access a geographically diverse sample ${ }^{36}$. The Australian attendees at this conference were approximately 900. Using an industry standard confidence interval of 95 per cent and margin of error of 5 per cent the sample size required to allow generalisability from the survey was $270^{37}$.
Table 1: Demographic data of respondents

\begin{tabular}{|c|c|}
\hline Role title $(n=124)$ & $\begin{array}{c}\text { Number } \\
\text { (percentage) }\end{array}$ \\
\hline $\begin{array}{l}\text { Director or Assistant } \\
\text { Director of Nursing }\end{array}$ & $2(1.6 \%)$ \\
\hline Nurse Practitioner & $3(2.4 \%)$ \\
\hline $\begin{array}{l}\text { Nurse Unit Manager } \\
\text { or Assistant Unit } \\
\text { Manager }\end{array}$ & $18(14.5 \%)$ \\
\hline Nurse Educator & $16(12.9 \%)$ \\
\hline $\begin{array}{l}\text { Perioperative Nurse } \\
\text { Surgeon's Assistant }\end{array}$ & $5(4 \%)$ \\
\hline $\begin{array}{l}\text { Clinical Nurse } \\
\text { Specialist / } \\
\text { Consultant }\end{array}$ & $19(15.3 \%)$ \\
\hline $\begin{array}{l}\text { Registered Nurse / } \\
\text { Clinical Nurse }\end{array}$ & $58(46.7 \%)$ \\
\hline $\begin{array}{l}\text { Enrolled Nurse / } \\
\text { Endorsed Enrolled } \\
\text { Nurse }\end{array}$ & $1(0.8 \%)$ \\
\hline $\begin{array}{l}\text { Anaesthetic } \\
\text { Technician }\end{array}$ & $1(0.8 \%)$ \\
\hline Other & $1(0.8 \%)$ \\
\hline \multicolumn{2}{|c|}{ State where practising $(n=124)$} \\
\hline Victoria & $24(19.3 \%)$ \\
\hline New South Wales & $26(20.9 \%)$ \\
\hline Queensland & $42(33.8 \%)$ \\
\hline Northern Territory & $4(3.2 \%)$ \\
\hline Western Australia & $10(8 \%)$ \\
\hline South Australia & $8(6.4 \%)$ \\
\hline Tasmania & $6(4.8 \%)$ \\
\hline $\begin{array}{l}\text { Australian Capital } \\
\text { Territory }\end{array}$ & $4(3.2 \%)$ \\
\hline \multicolumn{2}{|c|}{ Region of practice $(n=124)$} \\
\hline Metropolitan & $71(57 \%)$ \\
\hline Regional & $43(34 \%)$ \\
\hline Rural & $7(0.5 \%)$ \\
\hline $\begin{array}{l}\text { This question is not } \\
\text { applicable to my role }\end{array}$ & $3(0.2 \%)$ \\
\hline
\end{tabular}




\section{Survey/tool}

The survey/tool was developed by the first author $(\mathrm{TH})$, who is a member of ACORN and an NMSA currently practicing in Australia. Pilot testing was undertaken by six health professionals assessing face validity. Content validity was assessed by a group of perioperative staff and NMSAs. No reliability assessment e.g. test-retest, alternative-form testing, was undertaken ${ }^{38}$.

\section{Results}

A total of 124 surveys were started with a completion rate of 93 per cent $(n=116)$. As outlined in Table 1 , respondents were predominately Registered/Clinical Nurses (46.7 per cent, $n=58)$, Clinical Nurse Consultants (15.3 per cent, $n=19$ ) and Nurse Unit Managers (14.5 per cent, $n=18$ ). The highest number of respondents came from Queensland (33.8 per cent, $\mathrm{n}=42$ ) and the largest group worked in a metropolitan area (57 per cent, $n=71$ ).

As outlined in Table 2, of roles exclusive to the NMSA role, Perioperative Nurse Surgeon's Assistant (PNSA) was the most familiar with 83.6 per cent $(n=102)$ of respondents currently working with an NMSA in their unit. The generalist role of NP scored 95 per cent $(n=116)$, which is higher than PNSA but NPS work in many specialties in the health care system. Perioperative Nurse Practitioners who work as NMSAs scored 51.6 per cent $(n=63)$, much lower than the PNSA.

The specialty with the highest involvement of NMSAs in this survey was orthopaedics surgery (39.8 per cent, $n=49)$, followed by general surgery with (33.3 per cent, $n=41$ ). For uptake in other surgical specialties see Table 2. Utilisation was highest in metropolitan private perioperative units.
Table 2: Experience with the non-medical surgical assistant

\begin{tabular}{|l|c|}
\hline Familiarity with role titles $(\mathrm{n}=122)$ & $\begin{array}{c}\text { Number } \\
\text { (percentage) }\end{array}$ \\
\hline Non-Medical Surgical Assistant (NMSA) & $37(30.3 \%)$ \\
\hline Perioperative Nurse Surgeon's Assistant (PNSA) & $102(83.6 \%)$ \\
\hline Nurse Practitioner (NP) & $116(95 \%)$ \\
\hline Perioperative Nurse Practitioner (PNP) & $63(51.6 \%)$ \\
\hline Registered Nurse First Assistant (RNFA) & $68(55.7 \%)$ \\
\hline Physician Assistant (PA) & $46(37.7 \%)$ \\
\hline
\end{tabular}

Do NMSAs work in your unit? $(n=122)$

\begin{tabular}{|l|c|}
\hline Yes & $42(43.4 \%)$ \\
\hline No & $75(61.4 \%)$ \\
\hline N/A & $5(4.1 \%)$ \\
\hline
\end{tabular}

Which clinicians have you worked with in the role of NMSA? $(n=122)$

\begin{tabular}{|l|c|}
\hline Enrolled Nurse (EN) & $19(15.5 \%)$ \\
\hline Registered Nurse & $45(36.8 \%)$ \\
\hline $\begin{array}{l}\text { Registered Nurse with a graduate certificate surgical } \\
\text { assisting qualification }\end{array}$ & $28(22.9 \%)$ \\
\hline $\begin{array}{l}\text { Registered Nurse with a graduate diploma surgical } \\
\text { assisting qualification }\end{array}$ & $22(18 \%)$ \\
\hline $\begin{array}{l}\text { Registered Nurse with a master's degree surgical } \\
\text { assisting qualification }\end{array}$ & $23(18.8 \%)$ \\
\hline Perioperative Nurse Practitioner & $14(11.4 \%)$ \\
\hline Physician Assistant & $6(4.9 \%)$ \\
\hline $\begin{array}{l}\text { Allied Health Professional e.g. physiotherapist, } \\
\text { occupational therapist }\end{array}$ & $10(8.1 \%)$ \\
\hline Other & $2(1.6 \%)$ \\
\hline No experience & $49(40 \%)$
\end{tabular}

In which surgical specialties have you worked with an NMSA? $(n=123)$

\begin{tabular}{|l|c|}
\hline Cardiac/thoracic/vascular surgery & $22(17.8 \%)$ \\
\hline General/paediatric surgery & $41(33.3 \%)$ \\
\hline Neurosurgery & $11(8.9 \%)$ \\
\hline Orthopaedic surgery & $49(39.8 \%)$ \\
\hline Otolaryngology/head and neck/ENT surgery & $8(6.5 \%)$ \\
\hline Plastic/reconstructive/cosmetic surgery & $33(26.8 \%)$ \\
\hline Urology & $20(16.2 \%)$ \\
\hline Gynaecology/obstetrics/fertility & $32(26 \%)$ \\
\hline Ophthalmology & $6(4.6 \%)$ \\
\hline Other & $2(1.6 \%)$ \\
\hline
\end{tabular}


Figure 1: Perceived skill level of nurses working in the role of Non Medical Surgical Assistant



Respondents were asked how often they were required to perform the role of surgical assistant on an 'ad hoc' basis due to the absence of a designated surgical assistant. This occurred daily for 17 per cent of respondents $(n=21)$, once a week for 18.7 per cent $(n=23)$ and once or twice a month for 22 per cent $(n=27)$. The most common circumstance for this was 'out of hours emergency' (52.4 per cent, $n=64)$, 'pre-arranged assistant didn't show up or needs to leave early' (29 per cent, $n=36$ ) and 'regular session with no prearranged assistant' (24.5 per cent, $\mathrm{n}=30$ ). When asked to indicate how often a number of different clinicians performed the role of surgical assistant, 21.9 per cent of respondents $(n=23)$ indicated the instrument nurse did so, on a daily basis.

Perceived skill level of the various nurses working in the role of NMSA are outlined in Figure 1. ENs and RNs with no NMSA qualifications were rated 'poor/fair' a higher proportion of the time across all categories (mentoring, leadership, theatre efficiencies, safety and procedural knowledge) compared to RNs with an NMSA qualification and NPs who were predominately rated 'good' or 'very good / excellent'. Non-nursing NMSA numbers were too low for a comparison.

Regarding governance of the NMSA role in Australia, the majority of respondents (88.4 per cent, $n=107$ ) thought the Australian Health Practitioner Regulation Agency (AHPRA) via the Nursing and Midwifery Board Australia (NMBA) should participate in the governance process and 52 per cent $(n=63)$ thought the Royal Australasian College of Surgeons (RACS) should have input into governance of the role.

\section{Discussion}

While the sample of respondents did not reach the statistically significant figure of $n=270$, this is the first attempt at surveying perioperative staff across Australia about their perceptions and knowledge of the role of the NMSA. Completion rate of respondents was 92 per cent. Responses indicate the role of NMSA in Australia is not yet a mainstream role with more than half of the respondents (61.4 per cent, $n=75$ ) not incorporating NMSAs in their units and (40 per cent, $n=49$ ) having no experience with an NMSA at all. It is difficult to encourage nurses to participate in a survey where they are unable to see its relevance ${ }^{35}$ and lack of exposure to the NMSA role would reinforce this irrelevance.

Three interesting points were highlighted in this survey: 
1. Perioperative staff members are required to fill the role of surgical assistant on an impromptu basis

If perioperative staff members are required to fill the role of surgical assistant this would add weight to the argument that a need exists in the Australian health care system for the role of the NMSA. The first issue this raises is that the health care facility must provide a staff member in this situation. The second issue of concern is that, while some of the tasks performed by perioperative staff members who fill in as surgical assistants may seem very rudimentary - for example 'pointing the camera' for vision during laparoscopic procedures - using untrained assistants has implications related to medico-legal outcomes and patient safety in the event of a complication both intraoperatively and in the postoperative period ${ }^{39}$. Staff who perform but are not formally designated to the role of surgical assistant leave themselves exposed to organisational and medico-legal ramifications ${ }^{40}$.

2. The instrument nurse is performing a dual role of surgical assistant, in some cases, on a daily basis

Twenty-two per cent of respondents indicated that the instrument nurse was required to also perform the role of surgical assistant on a daily basis. Standards of practice from both ACORN and the Association of Perioperative Registered Nurses (AORN), the peak perioperative nursing body in the United States of America, state that the NMSA cannot concurrently function as an instrument nurse and cannot partake in the counting procedure ${ }^{41,42}$. When the instrument nurse is also performing the surgical assistant role, patient safety is considered to be compromised. This compromise is related to issues with establishing priorities between assisting the surgeon and conducting a comprehensive count ${ }^{43}$.

3. NMSAs with no post-graduate qualifications are perceived by perioperative staff to be less equipped in the skills of mentoring, leadership, theatre efficiencies, safety and procedural knowledge.

This poses the question: What differences in their ability to execute advanced practice tasks exist between diploma-prepared ENs, degree-prepared RNs, RNs with post-graduate NMSA qualifications and master's level NPs? ${ }^{44}$ The differences in specialty practice and advanced practice lie in the level of education which, in turn, promotes the clinician's ability to execute complex tasks ${ }^{45}$.

Regarding governance of the NMSA role in Australia, almost 85 per cent of respondents thought AHPRA via the NMBA should govern this role. This would ensure that the role of NMSA in Australia was a nursing role based on a nursing model of care. This varies from some of the international NMSA roles that have developed based on the medical model of care rather than patient-centred care.

\section{Limitations}

Surveys are considered a costeffective mode of collecting information across an immense array of clinicians and practice settings ${ }^{46}$ : however, surveys of health care providers are characterised by low response rates ${ }^{35,47}$. Low response rates raise concerns about the generalisability of the results. Nurses are reluctant to participate in a survey if the value or relevance is not clear ${ }^{35}$. As the role of NMSA is not a mainstream health care role in Australia, many nurses are not familiar with the title or the role. Entry in a draw of a non-monetary prize was used as incentive to participate in the survey but this technique has been shown to yield varying success ${ }^{35,46}$.

\section{Conclusion}

A need exists in the Australian health care system for the NMSA role. This need is reinforced by perioperative staff reporting they regularly fill in for absent surgical assistants when there is no pre-arranged assistant, the pre-arranged assistant needs to leave and in out-of-hours cases. Survey findings also indicate that the dual role of instrument nurse and surgical assistant is being performed in Australian perioperative units. Support for the formal recognition and regulation of the NMSA role in Australia is evidenced by perioperative staff perception that NMSAs with a higher level of qualification consistently perform tasks related to mentoring, leadership, theatre efficiencies and procedural knowledge at a 'good' or higher level. In the interests of patient safety, a dialogue should commence between ACORN, the Royal Australasian College of Surgeons and the Nursing and Midwifery Board of Australia to determine the best approach for recognising, educating and professionally regulating the NMSA role in Australia.

\section{References}

1. Institute of Medicine (US) Committee on the Robert Wood Johnson Foundation Initiative on the Future of Nursing at the Institute of Medicine. The Future of Nursing: Leading Change, Advancing Health. 2011.

2. Duff J. The Global Nursing Leadership Institute. ACORN 2014;27(4):36.

3. East R. Becoming a perioperative nurse practitioner: My journey. ACORN 2015;28(3):49. 
4. Bauer JC. Nurse practitioners as an underutilized resource for health reform Evidence-based demonstrations of costeffectiveness. J Am Acad Nurse Pract 2010;22(4):228-231.

5. Bryant E. Perioperative Nurse Surgeon's Assistants in day surgery an emerging role within Australia's health system. Ambulatory Care. 2010(July):25-27.

6. Fund M, Swanson-Hill A. Cost-effectiveness of the Nurse Practitioner. Kansas Nurse 2014;89(1).

7. Lynn A, Brownie S. The Perioperative Nurse Surgeon's Assistant: Issues and challenges associated with this emerging advanced practice nursing role in Australia. Collegian 2014;22(1):109-115 [cited 2016 Jun 3]. Available from: www.collegianjournal.com/article/ S1322-7696(13)00129-7/fulltext.

8. Hamlin L, Dobson J, Cook L. Perioperative nurse practitioners (NP) - the first two perioperative NPS are authorised in NSW. ACORN 2010;23(4):6-10.

9. Hains T, Strand H, Turner C. A selected international appraisal of the role of the Non-Medical Surgical Assistant. ACORN 2017;30(2):37-42.

10. Ireland S, Osbourne S. Reviewing ACORN Nursing role' Anaesthetic nurse'. ACORN 2016;29(4):54-57.

11. Battie R, Steelman V. Accountability in nursing practice: Why it is important for patient safety. ACORN 2015;28(4):14-16.

12. Hains T, Turner C, Strand H. Practice audit of the role of the Non-Medical Surgical Assistant in Australia, an online survey. Int J Nurs Pract 2016;22:546-555. doi: 10.1111/ ijn.12462.

13. Australian Institute of Health and Welfare. Surgery in Australian hospitals 2010-11. Canberra: AlHW; 2012.

14. Abraham J. Innovative perioperative role improves patient and organisational outcomes in minimally invasive surgery. J Perioper Pract 2011;21(5):158-164.

15. Hooker R, Harrison K, Pashen D. Are Australians willing to be treated by a physician assistant? AMJ 2010;3(7):407-413.

16. Kuilman L, Nieweg R, van der Schans C, Strijbos J, Hooker R. Are Dutch patients willing to be seen by a physician assistant instead of a medical doctor? Hum Resour Health 2012;10(28). DOI: 10.1186/1478-449110-28

17. Wilson LN, Wainright GA, Stehly CD, Stoltzfus J, Hoff WS. Assessing the academic and professional needs of trauma nurse practitioners and physician assistants. J Trauma Nurs 2013;20(1):51-55.

18. Pear SM, Williamson TH. The RN first assistant: An expert resource for surgical site infection prevention. AORN J 2009;89(6):1093-1097.
19. Martin S, Purkayastha S, Massey R, Paraskeva P, Tekkis P, Kneebone $\mathrm{R}$ et al. The Surgical Care Practitioner: A feasible alternative. Results of a prospective 4-year audit at St Mary's Hospital Trust, London. Ann R Coll Surg Engl 2007;89(1):30-35.

20. Hickey NC, Cooper K. Varicose vein surgery performed by a surgical care practitioner. Phlebology 2009;24(1):43-45.

21. Rothrock J, Seifet P. Assisting in Surgery Patient-centred care. $1^{\text {st }}$ ed. New York: $\mathrm{CCl}$ Competency and Credentialing Publishing; 2009.

22. New Zealand Nurses Organisation. Registered Nurse First Surgical Assistant in operating theatres in New Zealand: Service policy guidelines. Wellington: NZNO; 2009.

23. Mikhail J. Midlevel practitioner role evolution in an American College of Surgeons-verified trauma surgery service: The 23-year experience at Hurley Medical Center. J Trauma Nurs 2009;16(1):33-40.

24. Abbott S, Dadabhoy S, Dalphinis J, Hill M, Smith R. Professionalization in new primary care roles. Practice nursing 2007;18(8):413-417.

25. Jones A, Arshad H, Nolan J. Surgical care practitioner practice: One team's journey explored. J Perioper Pract 2012;22(1):19-23.

26. Collins J, Hillis D, Stitz R. Task Transfer: The view of the Royal Australasian College of Surgeons. Med J Aust 2006;185(1):25-26.

27. Quick J, Hall S, Jones A. The Surgical Care Practitioner role problems and possible solutions from nurses in the UK offered to RNFSA colleagues in New Zealand. Dissector. 2014;42(1):32-34.

28. Aning J. Surgical care practitioners are having a detrimental effect on surgical training. BMJ Careers 2006 Sep 9 [cited 2015 Nov 10]. Available from: careers.bmj.com/ careers / advice / view-article.html?id=1896.

29. Quick J. The role of the surgical care practitioner within the surgical team. BJN 2013;22(13):759-765.

30. Al-Hashami J. The role of the advanced scrub practitioner. J Perioper Pract 2007;17(2):76-80.

31. Dimond B. Legal Aspects of Nursing. $5^{\text {th }}$ ed. England: Pearson Education Ltd; 2008.

32. Health Workforce Australia. The potential role of Physician Assistants in the Australian context Volume 2 - Literature Review. Adelaide: HWA; 2012.

33. Field A, Arcus K, Whitehead R, Nadan R, Dale-Gandar L, Hanham G. Registered Nurse First Surgical Assistant pilot evaluation. Wellington: Health Workforce New Zealand; 2012
34. Smith C, Hains T, Mannion N. An opportunity taken: Sunshine Coast University Private Hospital's Perioperative Nurse Surgical Assistant experience. ACORN 2016;29(3):23-28.

35. VanGeest J, Johnson TP. Surveying nurses: Identifying strategies to improve participation. Eval Health Prof 2011;34(4):487-511.

36. Gillespie BM, Chaboyer W, Wallis M. Sampling from one nursing specialty group using two different approaches. Journal of Advanced Perioperative Care. 2010;4(2):78-85.

37. Survey Sample Size Calculator [Internet]. Ottawa: Fluid Surveys; 2017 [cited 2016 Jun 20]. Available from: fluidsurveys.com/ survey-sample-size-calculator/.

38. Litwin M. How to Measure Survey Reliability and Validity. New York: Sage Publication; 1995.

39. Hall SL, Quick J, Hall A, Jones A. Surgical Assistance - who can help? Ann R Coll Surg Engl 2014;96:244-246.

40. Brennan B. The registered nurse as a first surgical assistant: The 'downunder' experience. Seminars in Perioperative Nursing. 2001;10(2):108-114.

41. Australian College of Operating Room Nurses Ltd. Standards for Perioperative Nursing in Australia $14^{\text {th }}$ Ed. Adelaide, South Australia: ACORN; 2016.

42. Association of periOperative Registered Nurses (AORN). AORN Position Statement on RN First Assistants [Internet]. Denver: AORN; 1984 [updated 2013 Dec; cited 2016 Aug 10]. Available from: https://www.aorn. org/guidelines/clinical-resources/positionstatements.

43. Riley R, Manias E, Polglase A. Governing the surgical count through communication interactions: Implications for patient safety. Qual Saf Health Care 2006;15(5):369-674.

44. Jacob ER. Educators' expectations of roles, employability and career pathways of registered and enrolled nurses in Australia. Nurse Educ Pract 2016;16(1):170-175.

45. Thoun DS. Specialty and Advanced Practice Nursing: Discerning the differences. Nurs Sci Q 2011;24(3):216-222.

46. Vangeest JB, Johnson TP. Surveying clinicians: An introduction to the special issue. Eval Health Prof 2013;36(3):275-278.

47. Cho YI, Johnson TP, Vangeest JB. Enhancing surveys of health care professionals: A meta-analysis of techniques to improve response. Eval Health Prof 2013;36(3):382-407. 